\title{
Review
}

\section{E-cigarette Risk Factors and Effects on Adolescent Health in the}

\section{United States}

\author{
Elizabeth Afibah Armstrong-Mensah ${ }^{1 *}$, Deja Woolcock ${ }^{1}$, Jennifer Jisoo Jeon ${ }^{1} \&$ Puru Gaur ${ }^{2}$ \\ ${ }^{1}$ Georgia State University, Atlanta, Georgia, United States \\ ${ }^{2}$ Emory University, Atlanta, Georgia, United States \\ * Elizabeth Armstrong-Mensah, Georgia State University, Atlanta, Georgia, United States
}

Received: October 25, 2019 Accepted: November 7, 2019 Online Published: November 18, 2019

doi:10.22158/rhs.v4n4p357 URL: http://dx.doi.org/10.22158/rhs.v4n4p357

\begin{abstract}
Despite their adverse health effects, e-cigarette use has increased considerably among adolescents (people aged 10-19 years) in the United States. This is due to a number offactors including peer pressure, the availability of a variety of e-liquid flavors, the targeted marketing of these products to adolescents, and the belief by adolescents that e-cigarettes are less harmful to health than tobacco products. Just as traditional tobacco products, e-cigarettes have been found to be harmful to health and responsible for multiple adverse health conditions in adolescents, including inhibited growth and development, poor mental health, certain cancers, lung damage, nicotine dependency, future drug use, and social stigmatization. While the United States government realizes the harmful effects of e-cigarettes on adolescents, and although it has put in place certain policies to regulate the issue, e-cigarette use continues to be a public health problem among adolescents. This article discusses e-cigarettes, their use, risk factors, and health effects on adolescents in the US. It also proposes strategies for safeguarding adolescent health.
\end{abstract}

\section{Keywords}

E-cigarette, adolescents, risk factors, health effects, United States

\section{Introduction}

Tobacco use increases the risk of lung cancer, cardiovascular and respiratory diseases, as well as premature death (Grana, Benowitz, \& Glantz, 2014). In the past two decades, several global efforts have been made to reduce tobacco use among smokers. As part of its contribution to the global efforts, the government of the United States (US) issued health warnings, called for product labeling, conducted mass media campaigns, disseminated Surgeon General warnings, imposed bans on advertisements, and 
promoted nationwide programs on clean indoor air. In the bid to supposedly find an alternative to tobacco use, and to supplement traditional cigarette use, a new device with an electronic nicotine delivery system (ENDS), also known as an electronic cigarette (e-cigarette) was created.

The first known e-cigarette was created by Hon Lik, a Chinese chemist in 2003, as a safer tobacco cessation alternative for smokers in China. Since then, many e-cigarette industries have emerged and created many variations of the device. Thus, at present, there are over 400 e-cigarette brands, and over 7,000 e-liquid flavor options on the market (Lichtenberg, 2017). E-cigarettes were first introduced into the US in 2007, and have since become increasingly popular among adolescents. With the misconception that e-cigarettes are less harmful than regular tobacco cigarettes, a significant number of adolescents in the US are currently using them (Bach, 2019). Per the Centers for Disease Control and Prevention (CDC), in 2016, over 2 million US middle and high school students had used e-cigarettes within a 30-day period (Centers for Disease Control and Prevention, 2019). Given the current level of utilization, there are growing concerns about the long-term effects of the product on adolescent health, and the possibility of potential adolescent transition to tobacco products. Mirroring the tobacco industry's marketing strategies for cigarettes, including the utilization of celebrity endorsements, slick TV and magazine advertisements, and sports and music sponsorships, e-cigarette advertising is getting the attention of adolescents (Hansen, Hanewinkel, \& Morgenstern, 2018). Recognizing the public health issues associated with e-cigarette use among adolescents, the US Surgeon General issued an e-cigarette advisory for adolescents and called for aggressive national steps to stop the sale of e-cigarettes to adolescents (U.S. Department of Health and Human Services, 2016).

Regardless of the mechanisms put in place by the US Food and Drug Administration (FDA) to address e-cigarette use among adolescents, the practice continues to prevail and has become a public health issue. This article discusses e-cigarettes, their use, risk factors, and health effects on adolescent health in the US. It also proposes strategies for safeguarding adolescent health.

\section{E-cigarettes}

Also known as e-hookahs, hookah pens, vapes, vape pens, and mods, e-cigarettes are ENDS. They come in different shapes and sizes, are often battery-operated, and have a heating element and a place to hold liquid. Some e-cigarettes look like traditional tobacco cigarettes, while others look like cigars, pipes, pens, and even universal serial bus (USB) flash drives (Truth Initiatives Inspiring Tobacco-free Lives, 2018). E-cigarettes are either disposable or reusable. The disposable devices do not have rechargeable batteries and are often non-refillable (Brown \& Cheng, 2014). When heated up, e-cigarettes produce an aerosol that is inhaled by users into their lungs. The aerosol produced usually contains nicotine, flavorings, chemicals, and nano-engineered particles (U.S. Department of Health and Human Services, 2018). Although e-cigarettes share a basic design, there are engineering variations and user modifications, which result in differences in nicotine delivery and potential product risks (Brown \& Cheng, 2014). To date, there are four generations of e-cigarettes. 
First-generation e-cigarettes, also known as "cig-a-like", look very much like regular tobacco cigarettes. They are cheap, easily accessible, and disposable. Second-generation e-cigarettes are known as "personal vaporization". They look like pens or laser pointers, are larger than first-generation e-cigarettes, and can be recharged. They have a larger battery capacity, which supports longer vaping periods (Beltens, 2015). Its voltage adjustment feature allows users to adjust the level of heating for longer vaping periods. Third generation e-cigarettes are larger than first- and second-generation e-cigarettes. They typically have a box or cylindrical shape, have huge and sometimes customizable batteries, and some replaceable parts, hence the reason they are sometimes referred to as "mods". These devices are rechargeable. Fourth-generation e-cigarettes are the most recent products on the market and are smaller compared to previous generations. The unique features of fourth-generation e-cigarettes are the temperature control function and the ability it offers to breathe in larger puff volumes of aerosol. These two features allow a significant amount of e-liquid to be used per puff. JUUL is an example of a fourth-generation e-cigarette (Protano et al., 2018).

Nicotine levels in e-cigarettes vary, with some reaching levels as high as that of combustible cigarettes. For example, JUUL claims their products have a nicotine content just like traditional cigarettes and deliver nicotine up to 2.7 times faster than other e-cigarettes - many users are unaware of this fact (Truth Initiatives Inspiring Tobacco-free Lives, 2018). A recently published Truth Initiative study found that among adolescents, youth, and young adult JUUL users, only 37 percent knew that the product contained nicotine (Truth Initiatives Inspiring Tobacco-free Lives, 2018). In another study conducted by the National Institutes of Health researchers about what they thought might be present in e-cigarette juices, 66 percent of adolescents said just flavoring, 13 percent did not know, 13 percent said nicotine, 6 percent said marijuana, and 1 percent said other (National Institute on Drug Abuse; National Institutes of Health; U.S. Department of Health and Human Services, 2016).

\section{E-liquids}

E-liquids are the liquids that are converted into vapor by e-cigarette devices. While there are several different types, they all contain nicotine, flavorings, propylene glycol, and glycerin. E-liquid flavors are appealing to adolescents, but unbeknownst to them, are harmful to their health. Once heated, e-liquids are aerosolized and produce vapor that contains harmful elements such as lead, cadmium, and nickel, and harmful chemicals such as formaldehyde, hydrocarbons (Lichtenberg, 2017), and benzaldehyde. Benzaldehyde, a key ingredient in natural fruit flavors, has been found to cause irritation of respiratory airways. A recent study detected benzaldehyde in 108 of the 145 e-liquid flavors on the market, with cherry-flavored products accounting for the highest levels (Kosmider et al., 2016). E-cigarettes increase the risk of high blood pressure and diabetes among adolescents. They also contain agents that can cause bronchiolitis obliterans and other health conditions. This is unsettling, as e-cigarettes were originally created to be marketed as safer alternatives to traditional cigarette products (Lanza, Russell, \& Braymiller, 2017). 


\section{Adolescent E-cigarette Use}

According to the Department of Health and Human Services, e-cigarette use among adolescents in the US has greatly increased. Between 2011 and 2013, e-cigarette use rose by 69 percent among adolescents, and tripled from 2013 to 2014, exceeding that of traditional cigarette use among adolescents during that period (Lanza, Russell, \& Braymiller, 2017). In 2014, an estimated 2.46 million middle and high school students were using e-cigarettes. That number rose to three million in 2015, and between 2011 and 2015, usage increased by 900 percent among high school students (Lichtenberg, 2017).

Although 40 states in the US have laws prohibiting e-cigarette sales to minors (people under the age of 18), this population still has easy access to the product (Williams, Derrick, \& Ribisl, 2015). The national Monitoring the Future survey (MTF) found that in 2015, eighth and tenth grader e-cigarette use was 9.5 and 14 percent respectively, over two times that of conventional cigarette use (Johnston, O' Malley, Miech, Bachman, \& Schulenberg, 2016). Based on national data of high school students from the Youth Risk Behavior Surveillance, 45 percent of adolescents reported ever using electronic vaping devices, and 24 percent reported current use (Kann et al., 2016).

According to data from the 2017 National Youth Tobacco Survey (NYTS), about 12 percent of high school students and 3 percent of middle school students had used e-cigarettes in the last 30 days, compared to 2 percent of high school and 0.6 percent of middle school students who reported current use in 2011. Between 2017 and 2018, the percentage of high school students who self-reported having used e-cigarettes in the past 30-days increased by over 75 percent, and that for middle school-age children increased by approximately 50 percent (U.S. Department of Health and Human Services, 2018). MTF survey data revealed that males were significantly more likely to use e-cigarettes than females, especially in higher grades (Johnston, O’ Malley, Miech, Bachman, \& Schulenberg, 2016). The Florida Youth Tobacco Survey of middle and high school students collected in 2014, found no significant gender difference in current e-cigarette use by middle school students, but found that in high school, males were significantly more likely to be current e-cigarette users.

\section{Adolescents E-cigarette Risk Factors}

Several factors, including flavors, advertisements, peer pressure, e-cigarette marketing, and online commerce, predispose adolescents to e-cigarette use in the US.

\subsection{Flavors}

A recent study conducted between 2013 and 2014, found that the leading cause of e-cigarette use among the youth in the US was the availability of appealing flavors. According to industry-related documents, e-cigarette manufacturers are aware of this fact and have capitalized on this and targeted adolescents in their sales (Carpenter, Wayne, Pauly, Koh, \& Connolly, 2005). Most adolescents who now smoke tobacco cigarettes are said to have begun with smoking e-cigarette flavored products (Ambrose et al., 2015). In 2014, NYTS data showed that 63 percent of youth (1.58 million) who used tobacco that year, had previously used flavored e-cigarettes (Corey, Ambrose, Apelberg, \& King, 2015). Also, a recent 
national survey found that 81 percent of adolescents who now use e-cigarettes were initiated through the use of flavored products (Ambrose et al., 2015). Flavored e-cigarettes are a public health concern not only because they contribute to adolescent experimentation, but because the chemicals they contain are harmful to health (Allen et al., 2016).

\subsection{Advertisements}

E-cigarette manufacturers invest tens of millions of dollars in advertising their products (Fox, 2016). In 2014 alone, they invested about \$144 million in advertisements. In general, about seven out of 10 adolescents in the US are exposed to e-cigarettes advertisements (National Institute on Drug Abuse; National Institutes of Health; U.S. Department of Health and Human Services, 2016). Among middle school students, 53 percent are exposed to e-cigarette retail advertisements, 36 percent to internet advertisements, 34 percent to TV and movie advertisements, and 25 percent to newspaper and magazine advertisements. Among high school students, the numbers are slightly higher - 56 percent are exposed to retail advertisements, 43 percent to internet advertisements, 38 percent to TV and movie advertisements, and 35 percent to newspaper and magazine advertisements (National Institute on Drug Abuse; National Institutes of Health; U.S. Department of Health and Human Services, 2016). In its March 2016 edition of the Morbidity and Mortality Weekly Report, the CDC indicated that about four out of five middle and high school students in 2016 were exposed to e-cigarette advertisements from at least one of the sources listed. This is a 12 percent increase from 2014 (Centers for Disease Control and Prevention, 2017). E-cigarette advertisements make adolescents vulnerable and put them at risk of using e-cigarettes, as most of them include celebrities, have excellent design features and themes that focus on sex, independence, and rebellion, all of which greatly appeal to adolescents (Centers for Disease Control and Prevention, 2017).

\subsection{Peer Pressure}

E-cigarette use among adolescents in the US is now becoming a culture facilitated by peer pressure. Emotional instability, the desire to be recognized by peers and to be seen as "cool has led to increased e-cigarette use among adolescents. A recent study conducted by Barrington et al. found that favorable social perceptions of e-cigarettes by adolescents have contributed to the renormalization of tobacco products generally, and has created challenges for health officials in the US (Barrington-Trimis et al., 2015). Another study found that adolescents who had three or four of their closest friends using e-cigarettes were 104 times as likely than those with no friends using e-cigarettes, to become e-cigarette users themselves. These findings help to explain the increase in the number of adolescents using e-cigarettes in the last few years (Barrington-Trimis et al., 2015).

\subsection{E-cigarette Marketing}

Companies that sell e-cigarette products are able to utilize marketing strategies that traditional tobacco companies were and are still banned and restricted from using (Truth Initiatives Inspiring Tobacco-free Lives, 2018). In 1970, the Public Health Cigarette Smoking Act passed by the US Congress prevented traditional tobacco companies from advertising their products on national TV and on the radio (Truth 
Initiatives Inspiring Tobacco-free Lives, 2018). The Act made it compulsory for tobacco companies to include a warning on their packaging, stating the detrimental effects of smoking cigarettes on health. It also prohibited states and local governments from making additional laws on cigarette advertising. This aspect of the Act addressed the regulatory authority question, which had remained unaddressed for a while. It also required regulatory agencies to notify Congress six months prior to enacting any new policies on cigarette advertising (Brumage, 2017).

Since e-cigarette advertisements and marketing have not been restricted, manufacturers have expanded their reach to mobile platforms, including Instagram, Facebook, and YouTube (Truth Initiatives Inspiring Tobacco-free Lives, 2018). Many celebrities and social media influencers have endorsed, or sponsored content funded by e-cigarette companies and persuaded their audiences to purchase e-cigarettes (Truth Initiatives Inspiring Tobacco-free Lives, 2018). The subtle, but intentional placement of e-cigarette products in music videos coupled with young models using the products, also influence adolescents to purchase them.

\subsection{Online Commerce}

Utilizing their marketing tactics and advertisements, e-cigarette manufactures sell large quantities of their products via the internet. In 2015, the University of California in San Diego conducted a study on e-cigarette marketing with the aim of identifying internet vendor characteristics with a focus on geographic location, promotional strategies, use of social networking, age verification policies, and consumer warning representation. The results showed that of the 57 e-cigarette internet vendors, 31 (54 percent) primarily sell their products online (Mackey, Miner, \& Cuomo, 2015). About 40 (70 percent) of the internet vendors use more than one social network service, and 24 (42 percent) use more than one promotional sales strategy to sell their products online (Mackey, Miner, \& Cuomo, 2015). The University of California data also revealed that a majority of the vendors, 39 (68 percent), display health warnings, but in tiny fonts on their websites, or in their terms and conditions (Mackey, Miner, \& Cuomo, 2015).

Non-verification of purchaser age is also a problem with internet-based sales. According to the University of California study data, 20 (35 percent), internet vendors do not have an age verification process for online e-cigarettes sale (Mackey, Miner, \& Cuomo, 2015), thus, avoiding legal restrictions regarding minimum age requirements. Despite the fact that the sale of e-cigarettes to minors has been banned in 41 states, studies show that this population is able to purchase e-cigarettes online (Williams, Derrick, \& Ribisl, 2015). The unregulated nature of the online e-cigarette marketplace makes it easy for adolescents to purchase them (Mackey, Miner, \& Cuomo, 2015).

\section{Health Effects of E-cigarettes}

Although e-cigarettes negatively impact health, only 25 percent of high school students who use them are aware that they contain harmful substances (Anand, Mcginty, Obrien, Guenthner, Hahn, \& Martin, 2015). E-cigarettes typically contain toxins like nicotine that no one, including adolescents, should 
consume (Barrington-Trimis, Samet, McConnell, 2014). These toxins have been found to cause lung disease, affect brain development, and cause DNA damage and mutagenesis (Sandoiu, 2018).

\subsection{Lung Disease}

As of September 27, 2019, the CDC reported 805 cases of lung injuries associated with e-cigarette product use in 46 states and in one US territory. It also confirmed 10 deaths in 12 states (California, Florida, Georgia, Illinois, Indiana, Kansas, Minnesota, Mississippi, Missouri, and Oregon) (Centers for Disease Control and Prevention, 2019). Per the CDC, 72 percent of 383 cases of the total 805 reported cases were males, 67 percent were within the 18 to 34 age group, and 16 percent were under the age of 18 (Centers for Disease Control and Prevention, 2019). All patients reported a history of e-cigarette use and most reported using e-cigarette liquids that contained nicotine, tetrahydrocannabinol, cannabinoid oils, and other substances and additives (Centers for Disease Control and Prevention, 2019).

Inhaling aerosol emitted from e-cigarettes can have biological effects on the body of adolescents. A most common biological consequence of inhaling aerosol from e-cigarettes is oxidative stress. According to Burton and Jauniaux, oxidative stress arises when the production of reactive oxygen overwhelms the intrinsic antioxidant defenses of the body (Burton \& Jauniaux, 2011). In in-vitro research conducted by Munakata et al. (2018) significant oxidative stress activity was detected in human bronchial epithelial cells after exposure to e-cigarette aerosols. The ratio of glutathione to oxidized glutathione and the level of antioxidants were used as indicators for oxidative stress. The study used four different types of nicotine products, tobacco vapor products, heat-not-burn tobacco products, e-cigarettes, and a combustible cigarette to compare the effects of each product. The result from the study showed possible cell death and reduced function of lung health from the e-cigarette vapor inhalation (Munakata et al., 2018). Another study conducted by Queimado et al. (2018), further underscores the dangers associated with the utilization of e-cigarette products. In their study, they found induced DNA damage and reduced DNA repair in mice that were exposed to e-cigarette aerosols. The researchers found that the mice had increased DNA lesions, cell adducts, and impaired DNA repair function. This occurrence was found not to be due to variations in nicotine levels, but due to unidentified genotoxic ingredients in e-liquids. Findings from these two studies are critical because, they show that using e-cigarette products can cause lung cell death, or reduced lung function. It also makes a clear case for why e-cigarettes should not be used as an alternative to tobacco products by adolescents, as the aerosol they inhale, have toxic characteristics (Munakata et al., 2018).

\subsection{Brain Development}

The human brain is not fully developed until about age 25 . Thus, using e-cigarettes during adolescence can harm the parts of the brain that control attention, learning, mood, and impulse control (U.S Department of Health and Human Services, 2016). Every time a new memory is created, or a new skill is learned, stronger connections - or synapses - are built between brain cells. The brains of adolescents build synapses faster than adult brains. The ingestion of nicotine found in e-cigarette products can change 
the way these synapses are formed. The continued use of e-cigarettes may increase adolescent risk for addiction to other drugs (U.S Department of Health and Human Services, 2016).

\subsection{DNA Damage}

In their study to assess the effects of e-cigarette use on DNA damage, Dator and Balbo recruited five e-cigarette users. They collected saliva samples before and after 15-minutes of vaping. The collected samples were analyzed for chemicals that are known to damage DNA. To assess possible long-term effects of e-cigarette use, the team examined DNA damage in the cells of participants' mouths. Dator and Balbo found three DNA-damaging compounds; formaldehyde, acrolein, and methylglyoxal, whose levels increased in the saliva after e-cigarette use (American Chemical Society, 2018). According to the research, 80 percent of the e-cigarette users showed increased DNA damage due to acrolein exposure. The DNA damage occurs when toxic acrolein reacts with DNA. If the cell does not repair the damage in the usual natural way, cancer can occur. Although the study was done with a small sample, it points to the fact that if adolescents continue to use e-cigarettes, they could damage their DNA and put themselves at risk for cancer.

\section{Efforts to Regulate Adolescent E-cigarette Use}

\subsection{E-liquids}

In 2008, the US Food and Drug Administration (FDA) attempted to ban e-cigarettes. A year later, Sottera, an e-cigarette manufacturing company sued the agency on the grounds that, it did not have the authority to regulate e-cigarettes as drugs or drug delivery devices and could therefore, not stop shipments of the product into the country (Nguyen \& Aamodt, n.d.). In 2010, the FDA appealed the ruling of the lower court, but was unsuccessful in getting it overturned. In 2009, the FDA banned the marketing of all e-cigarette flavors (candy-like flavors, such as gummy bear, cotton candy, and apple) with the exception of menthol, as a means of regulating adolescent's e-cigarette use. This became necessary after the FDA's Division of Pharmaceutical Analysis (DPA) conducted a preliminary analysis of 18 flavored nicotine and no-nicotine e-cigarettes cartridges (Neporent, 2014). The flavors were tested for carcinogenic or harmful ingredients to humans. Findings indicated that the e-cigarettes cartridges sampled contained 1 percent diethylene glycol, an ingredient used in antifreeze that is toxic to humans. The e-cigarette cartridges that contained no nicotine had low levels of nicotine present ranging from $26.8-43.2 \mathrm{mcg}$ nicotine/100mL per puff (Etter, Zäther, \& Svensson, 2013). While the FDA ban is an excellent first step, public health experts and Democratic lawmakers say that it does not go far enough in addressing the issue of adolescent e-cigarette use. To them, the FDA should have banned all e-liquid flavors, including menthol, until such time that manufacturers can prove them to be safe.

\subsection{Marketing}

In 2014 , the FDA came up with a proposal that would give the agency the authority to regulate commercial sales of e-cigarettes as nontherapeutic tobacco products. However, the proposal failed to restrict online sales, ban the use of flavors, or curb the marketing and television advertising of e-cigarette 
products. This proposal in effect allowed e-cigarette companies to continue to sell their products to adolescents. In 2016, six health and tobacco-control organizations noted that, regardless of the FDA proposal, manufacturers went on to introduce new e-cigarette products at an alarming pace that was hard to keep up with (CounterTobacco.org, n.d.). They appeared to be in total defiance of the law, and unperturbed by potential FDA enforcement (McGinley, 2018).

\subsection{Packaging and Marketing}

In 2018, the FDA required e-cigarette manufacturers to include a nicotine warning statement on the package of all new products and to indicate that it is harmful to health using 12 font size and covering at least 30 percent of the package (Lichtenberg, 2017). The FDA also prohibited e-cigarette retailers from advertising their products without providing a health warning statement (Lichtenberg, 2017). The FDA's requirement is considered historical and critical in the enforcement of actions against e-cigarette manufacturers. This notwithstanding, adolescent access to e-cigarette products, retail restrictions, licensing, and smoke-free restrictions, vary from state to state. While California law requires e-cigarette cartridges and solutions for filling electronic cigarettes to be sold in child-resistant packaging, the state of Georgia has no packaging requirements at all.

Regarding marketing, in Hawaii, the sale and distribution of e-cigarettes are prohibited to persons under the age of 21, but in Illinois, the age of prohibition is 18 years (Truth Initiatives Inspiring Tobacco-free Lives, 2018). While states have the authority to tax e-cigarettes, to date, not all of them have implemented their own excise or special tax (non-sales tax) on e-cigarettes. Currently, only eight states and Washington, D.C., have imposed a tax on e-cigarettes.

\section{Recommendations}

Current efforts to regulate adolescent e-cigarette use in the US has been ineffective. To stem the tide, it is important to regulate the e-cigarette industry quickly and precisely before they gain lobbying powers similar to that held by big tobacco companies. Specifically, the federal government and the FDA need to ensure uniformity in regulations by getting all 50 states, US territories, and e-cigarette companies to have a common understanding of what constitutes tobacco products, ensure that mandatory warning labels are placed on all packaging, and that tamper-resistant packaging is used. The federal government and the FDA also need to ensure that all states have a standard age limit for e-cigarette use, vigorously promote the banning of e-cigarette products to adolescents, and enforce consequences for non-adherence to regulations.

\subsection{National Definition of Tobacco Products}

The Family Smoking Prevention and Tobacco Control Act amended the Federal Food, Drug, and Cosmetic (FD\&C) Act and gave the FDA the authority to regulate tobacco products. Section 201(rr) of the FD\&C Act (21 U.S.C. 321) defines the term "tobacco product" as any product made or derived from tobacco that is intended for human consumption, including any component, part, or accessory of a tobacco product (except for raw materials other than tobacco used in manufacturing a component, part, 
or accessory of a tobacco product). Excluded from this definition is any article that states that it is a drug, device, or combination product. This omission has left room for varying interpretations by e-cigarette companies and has empowered them to indicate that FDA is not permitted to regulate the nicotine in cigarettes as a drug and as such, should not be permitted to regulate e-cigarettes (Food and Drug Administration, HHS, 2018). These interpretations and perceptions have negatively affected the FDA's ability to successfully regulate e-cigarette use in the US.

To address the issue of term definition, the US Congress needs to amend the FD\&C Act to give the FDA additional authority to define what constitutes a tobacco product. The FDA also needs to work with e-cigarette manufacturers to ensure that there is a common understanding of what constitutes a tobacco product. This definition must be explicit and be broad enough to capture future e-cigarettes innovations as a tobacco product (Public Health Law Center, 2017). It must be popularized and adopted at the federal level and must be accepted and used by all 50 states and US territories. This effort will put the e-cigarette industry on notice and cause it to know that its activities can, and will be regulated by the FDA. A shared understanding of what constitutes a tobacco product will also empower states to uphold FDA consequences for violations.

\subsection{Mandatory Warning Labels and Tamper-Resistant Packaging}

E-cigarette manufacturers are currently not required to list all of the ingredients in their products (flavors), therefore, users, including adolescents, are unaware of what is contained in the products they are using. According to a recent publication by the National Institutes of Health, roughly 66 percent of teens who vape believe that their e-cigarette juices contain only flavoring (National Institute on Drug Abuse; National Institutes of Health; U.S. Department of Health and Human Services, 2016). According to data from the American Association of Poison Control Centers, in 2015, there were over 3,000 calls to poison control centers around the US as a result of exposure to e-cigarette liquids. About 70 percent of those calls were related to adolescent exposure (Public Health Law Center, 2017). This level of ignorance and unfortunate occurrences among adolescents justifies the need for mandatory warning labels on all packaging as is done with tobacco products in Australia (Tobacco Labelling Resource Centre, n.d.). The labels should be in large print (12 font size). They should very clearly list the potential harms of e-cigarettes and the ingredients they contain. This may curtail the use of these products by adolescents, especially in countries like the US where efforts to ban e-cigarettes has failed.

\subsection{Common Prohibition Age}

The federal government in conjunction with the FDA need to come up with a uniform age limit across the country and enact a policy that indicates the legal age at which one can have access to, or purchase e-cigarettes. Prohibiting the sale of e-cigarette products to people under the age of 21 is a preferable limit. This will require e-cigarette products to be kept behind the counter in stores, require people to show some form of identification prior to product purchase, and hold e-cigarette stores and "vaping lounges" accountable as licensed tobacco retailers. 


\subsection{E-cigarette Manufacturer Regulation}

Prohibiting e-cigarette manufacturers and retailers from making unsubstantiated marketing claims about the safety and benefits of their products is in the best interest of public and adolescent health. Lawmakers need to develop regulatory options designed to limit the targeted marketing of e-cigarettes to minors. International experience shows that advertising regulations that are stringent and comprehensive have a more significant impact on lowered overall tobacco and nicotine use among adolescents than the weaker, less comprehensive ones (U.S Food \& Drug Adminstration, 2018). There is conclusive evidence that e-cigarette products are emitting toxic substances and are posing a threat to the health of the nation's adolescents. Thus, it is critical for the federal government and the FDA to combat the problem with a focus on policy and the implementation of effective strategies that target the e-cigarette industry and its activities.

\subsection{Regulation of E-cigarette Sale}

The sale of e-cigarette products in the US should be restricted to adult-only facilities and the number of shops retailing these products must be limited. Regarding location, e-cigarettes shops should not be allowed to operate in neighborhoods or places close to schools. Self-service purchasing options such as vending machines should also be banned in favor of in-person transactions for all e-cigarette purchases. Campaigns that educate adolescents on the dangers of using tobacco products including e-cigarettes need to be launched and popularized throughout the country with a focus on the health effects of e-cigarettes just as was done by the CDC with its campaigns against tobacco use.

\section{Conclusion}

Contrary to the notion that e-cigarettes are less harmful and a better alternative to tobacco cigarettes, studies have shown that these products are just as dangerous and harmful to human health as tobacco cigarettes. While some state and local governments and retail shops in the US are taking steps to regulate the sale, marketing, and use of e-cigarettes in order to protect the health of adolescents and to reduce youth initiation to nicotine and tobacco products, not much has been achieved thus far. A lot more work still needs to be done. The government needs to be intentional and work with the FDA to come up with strategies and enact legislation to address those issues that hinder and stand in the way of successful e-cigarette regulation including; coming up with a common comprehensive national definition of what constitutes tobacco products across the country, ensuring that all states impose consistent (high) taxes on e-cigarette products, and holding e-cigarette companies accountable for the non-display of explicit, clear, and bold health risk warning labels on their products. The government and the FDA also need to establish policies that ensure that all states prohibit the sale of e-cigarette products to people under a common agreed age (preferably 21 years). As part of the national effort, the government needs to be on the alert for tobacco and e-cigarette industry attempts to shape laws that benefit their financial interests. Without political will and federal government commitment, it will be difficult to successfully regulate adolescent e-cigarette use in the US. 


\section{Acknowledgements}

The authors would like to thank Dr. Harry Heiman Georgia State University for his ideas during the research.

\section{References}

Allen, J. G. et al. (2016). Flavoring chemicals in e-cigarettes: Diacetyl, 2,3-pentanedione, and acetoin in a sample of 51 products, including fruit-, candy-, and cocktail-flavored e-cigarettes. Environ Health Perspect, 124(6), 733-739. https://doi.org/10.1289/ehp.1510185

Ambrose, B. K. et al. (2015). Flavored tobacco product use among US youth aged 12-17 years, 2013-2014. JAMA, 314(17), 1871-1873. https://doi.org/10.1001/jama.2015.13802

American Chemical Society. (2018). E-cigarettes can damage DNA. Science Daily website. Retrieved August 5, 2019, from https://www.sciencedaily.com/releases/2018/08/180820085208.htm

Anand, V., Mcginty, K. L., Obrien, K., Guenthner, G., Hahn, E., \& Martin, C. A. (2015). E-cigarette use and beliefs among urban public high school students in North Carolina. Journal of Adolescent Health, 57(1), 46-51. https://doi.org/10.1016/j.jadohealth.2015.03.018

Bach, L. (2019). Electronic cigarettes and youth. Campaign for tobacco-free kids website.

Barrington-Trimis, J. L. et al. (2015). Psychosocial factors associated with adolescent electronic cigarette and cigarette use. Pediatrics, 136(2), 308-317. https://doi.org/10.1542/peds.2015-0639

Barrington-Trimis, J. L., Samet, J. M., McConnell, R. (2014). Flavorings in electronic cigarettes: An unrecognized respiratory health hazard? JAMA, 312(23), 2493-2494. https://doi.org/10.1001/jama.2014.14830

Beltens, M. (2015). The 4 generations of electronic cigarettes. Ecigclopedia.com website. Retrieved August 31, 2015, from https://www.ecigclopedia.com/the-4-generations-of-electronic-cigarettes/

Brown, C. J., \& Cheng, J. M. (2014). Electronic cigarettes: Product characterisation and design considerations. Tob Control., 223, ii4-ii10. https://doi.org/10.1136/tobaccocontrol-2013-051476

Brumage, J. (2017). The Public Health Cigarette Smoking Act of 1970. Robert C. Byrd. Center for Congressional History and Education website. Retrieved October 8, 2019, from https://www.byrdcenter.org/byrd-center-blog/the-public-health-cigarette-smoking-act-of-1970

Burton, G. J., \& Jauniaux, E. (2011). Oxidative stress. Best Pract Res Clin Obstet Gynaecol, 25(3), 287-299. https://doi.org/10.1016/j.bpobgyn.2010.10.016

Carpenter, C. M., Wayne, G. F., Pauly, J. L., Koh, H. K., \& Connolly, G. N. (2005). New cigarette brands with flavors that appeal to youth: Tobacco marketing strategies. Health Affairs, 24(6), 1601-1610. https://doi.org/10.1377/hlthaff.24.6.1601

Centers for Disease Control and Prevention. (2017). E-cigarette Ads and Youth. Centers for Disease Control and Prevention website. Retrieved October 12, 2019, from https://www.cdc.gov/vitalsigns/ecigarette-ads/index.html 
Centers for Disease Control and Prevention. (2019). Electronic cigarettes. Centers for Disease Control and Prevention website. Retrieved October 8, 2019, from https://www.cdc.gov/tobacco/basic_information/e-cigarettes/index.htm

Centers for Disease Control and Prevention. (2019). Outbreak of lung injury associated with e-cigarette use, or vaping. Retrieved October 11, 2019, from https://www.cdc.gov/tobacco/basic_information/ e-cigarettes/severe-lung-disease.html

Corey, C. G., Ambrose, B. K., Apelberg, B. J., \& King, B. A. (2015). Flavored tobacco product use among middle and high school students-United States, 2014. Morbidity and Mortality Weekly Report (MMWR), 64(38), 1066-1070. https://doi.org/10.15585/mmwr.mm6438a2

CounterTobacco.org. (n.d.). E-cigarettes at the point of sale. CounterTobacco.org website. Retrieved October 8, 2019, from https://www.countertobacco.org/resources-tools/evidence-summaries/ecigarettes-at-the-point-of-sale/

Etter, J. F., Zäther, E., \& Svensson, S. (2013). Analysis of refill liquids for electronic cigarettes. Addiction, 108(9), 1671-1679. https://doi.org/10.1111/add.12235

Food and Drug Administration, HHS. (2018). Clarification of When Products Made or Derived From Tobacco Are Regulated as Drugs, Devices, or Combination Products; Amendments to Regulations Regarding "Intended Uses”; Partial Delay of Effective Date. Federal Register website. Retrieved October 12, 2019, from https://www.federalregister.gov/documents/2018/03/16/2018-05347/ clarification-of-when-products-made-or-derived-from-tobacco-are-regulated-as-drugs-devices-or

Fox, M. (2016). E-cigarette ads target millions of kids, CDC says. NBC News website. Retrieved August 5, 2019, from https://www.nbcnews.com/health/kids-health/e-cigarette-ads-targetmillions-kids-cdc-says-n490601

Grana, R., Benowitz, N., \& Glantz, S. A. (2014). E-cigarettes: A scientific review. Circulation, 129(19), 1972-1986. https://doi.org/10.1161/CIRCULATIONAHA.114.007667

Hansen, J., Hanewinkel, R., \& Morgenstern, M. (2018). Electronic cigarette marketing and smoking behaviour in adolescence: A cross-sectional study. ERJ Open Res., 4(4), 00155-2018. https://doi.org/10.1183/23120541.00155-2018

Johnston, L. D., O’ Malley, P., Miech, R., Bachman, J., \& Schulenberg, J. (2016). Monitoring the future national survey results on drug use, 1975-2015: Overview, key findings on adolescent drug use. Ann Arbor, MI: Institute for Social Research, The University of Michigan.

Kann, L. M. T. et al. (2016). Youth Risk Behavior Surveillance-United States, 2015. MMWR Surveill Summ., 65(No. SS-6), 1-174. https://doi.org/10.15585/mmwr.ss6506a1

Kosmider, L. et al. (2016). Cherry-flavoured electronic cigarettes expose users to the inhalation irritant, benzaldehyde. Thorax, 71(4), 376-377. https://doi.org/10.1136/thoraxjnl-2015-207895

Lanza, S. T., Russell, M. A., \& Braymiller, J. L. (2017). Emergence of electronic cigarette use in US adolescents and the link to traditional cigarette use. Addictive Behaviors, 67, 38-43. https://doi.org/10.1016/j.addbeh.2016.12.003 
Lichtenberg, K. (2017). E-Cigarettes: Current evidence and policy. Mo Med., 114(5), 335-338.

Mackey, T. K., Miner, A., \& Cuomo, R. E. (2015). Exploring the e-cigarette e-commerce marketplace: Identifying Internet e-cigarette marketing characteristics and regulatory gaps. Drug and Alcohol Dependence, 156, 97-103. https://doi.org/10.1016/j.drugalcdep.2015.08.032

McGinley, L. (2018). FDA investigating whether dozens of e-cigarette products are being illegally marketed. The Washington Post website. Retrieved October 8, 2019, from https://www.washingtonpost.com/health/2018/10/12/fda-investigating-whether-dozens-e-cigaretteproducts-are-being-illegally-marketed/

Munakata, S., Ishimori, K., Kitamura, N., Ishikawa, S., Takanami, Y., \& Ito, S. (2018). Oxidative stress responses in human bronchial epithelial cells exposed to cigarette smoke and vapor from tobaccoand nicotine-containing products. Regulatory Toxicology and Pharmacology, 99, 122-128. https://doi.org/10.1016/j.yrtph.2018.09.009

National Institute on Drug Abuse; National Institutes of Health; U.S. Department of Health and Human Services. (2016). Teens and E-cigarettes. Retrieved August 5, 2019, from https://www.drugabuse.gov/related-topics/trends-statistics/infographics/teens-e-cigarettes

Neporent, L. (2014). 5 Things to know about e-cigarettes. ABC News website. Retrieved August 6, 2019, from https://www.abcnews.go.com/Health/things-cigarettes/story?id=22782568

Nguyen, D., \& Aamodt, G. (n.d.). Electronic Cigarettes the Past, Present and Future. Dentalcare.com $\begin{array}{lllll}\text { website. } & \text { Retrieved } & \text { October } & \text { 8, 2019, }\end{array}$ https://www.dentalcare.com/en-us/professional-education/ce-courses/ce451/safety-and-regulationof-e-cigarette-use-in-the-us

Protano, C. et al. (2018). Environmental electronic vape exposure from four different generations of electronic cigarettes: Airborne particulate matter levels. Int J Environ Res Public Health, 15(10), 2172. https://doi.org/10.3390/ijerph15102172

Public Health Law Center. (2017). Regulating Electronic Cigarettes \& Similar Devices. Public Health Law Center website.

Sandoiu, A. (2018). The pros and cons of e-cigarettes revealed. Medical News Today website. Retrieved August 5, 2019, from https://www.medicalnewstoday.com/articles/320733.php

Tobacco Labelling Resource Centre. (n.d.). Australia. Tobacco Labelling Resource Centre website. Retrieved October 8, 2019, from https://www.tobaccolabels.ca/countries/australia/

Truth Initiatives Inspiring Tobacco-free Lives. (2018). E-cigarettes: Facts, stats, and regulations. Truth Initiative Inspiring Tobacco-free Lives website. Retrieved August 12, 2019, from https://www.truthinitiative.org/research-resources/emerging-tobacco-products/e-cigarettes-facts-st ats-and-regulations

U.S Department of Health and Human Services. (2016). E-cigarette use among youth and young adults: A report of the Surgeon General. Centers for Disease Control and Prevention website. 
U.S Food \& Drug Adminstration. (2018). Section 2 of the Tobacco Control Act Findings. U.S Food \& Drug Administration website. Retrieved July 8, 2019, from https://www.fda.gov/tobacco-products/rules-regulations-and-guidance/section-2-tobacco-control-a ct-findings

U.S. Department of Health and Human Services. (2016). Surgeon General's advisory on e-cigarette use among youth. A Report of the Surgeon General. U.S. Department of Health and Human Services, Centers for Disease Control and Prevention, National Center for Chronic Disease Prevention and Health Promotion, Office on Smoking and Health; 2016. Surgeon General website.

U.S. Department of Health and Human Services. (2018). Surgeon General releases advisory on E-cigarette epidemic among youth. U.S. Department of Health \& Human Services website. Retrieved August 5, 2019, from https://www.hhs.gov/about/news/2018/12/18/surgeon-generalreleases-advisory-e-cigarette-epidemic-among-youth.html

Williams, R. S., Derrick, J., \& Ribisl, K. M. (2015). Electronic cigarette sales to minors via the internet. JAMA Pediatrics, 169(3), e1563. https://doi.org/10.1001/jamapediatrics.2015.63 